\title{
Compromiso y técnica en la configuración del campo laboral de los derechos humanos en el gobierno de la ciudad de Buenos Aires
}

RMA

Antropología Social
Ana Guglielmucci

CONICET, Facultad de Filosofía y Letras, Universidad de Buenos Aires. E-mail: mucciana@hotmail.com

\begin{abstract}
Resumen
Desde mediados de la década del '90, la categoría "memoria sobre el terrorismo de Estado" fue institucionalizada a través de una serie de leyes y programas dentro del organigrama del Gobierno de la Ciudad Autónoma de Buenos Aires. Paralelamente, numerosos militantes de organizaciones de DD. HH. fueron incorporados como gestores, funcionarios y empleados, encargados de definirla e implementarla en el espacio urbano. En este artículo, describimos y analizamos las principales características que ha asumido el trabajo de cogestión entre agencias gubernamentales y organizaciones no gubernamentales de DD.HH. orientado a la "preservación y la promoción de la memoria". Y, destacamos de qué manera los requerimientos técnicos de este trabajo han sido articulados de un modo particular con aquellos valores ligados a la militancia en el campo de los DD. HH., como el compromiso político.
\end{abstract}

Palabras clave: Memoria, Estado, gobierno, técnica, compromiso.

Commitment and technique in the configuration of human rights field of work in the Buenos Aires city government.

\begin{abstract}
Since the mid-'90s, the category "memory of state terrorism" was institutionalized through a series of laws and programs within the organization of the Gobierno de la Ciudad Autonoma de Buenos Aires. Similarly, many human rigths's militants were incorporated as managers, officials and employees, responsible for formulating and implementing it in urban space. In this article, we describe and analyze the main characteristics that has made the job of co-management between government agencies and human rights non-governmental organizations aimed at "preserving and promoting the memory". And point out how the technical requirements of this work have been articulated in a particular way with those values associated with militancy in the field of DD.HH., as political commitment.
\end{abstract}

keywords: Memory, State, government, tehcnique, commitment.

Entre fines de la década del noventa y mediados del 2000, la categoría "memoria sobre el terrorismo de Estado" fue instituida como objeto de políticas públicas de Derechos Humanos (DD.HH.) dentro del organigrama del Gobierno de la Ciudad Autónoma de Buenos Aires (GCABA). Al mismo tiempo, integrantes de algunas organizaciones no gubernamentales de DD.HH., comúnmente denominadas "organismos" ${ }^{1}$, fueron incorporados a la estructura

1 Comúnmente se denomina de este modo al conjunto de
organizaciones caracterizadas por inscribir sus demandas en el marco
de la convención de los derechos del hombre y canalizarlas a través
de vías jurídicas. Ellas son: Abuelas de Plaza de Mayo, Asamblea
Permanente por los Derechos Humanos (APDH), Asociación Madres
de Plaza de Mayo, Centro de Estudios Legales y Sociales (CELS),
Familiares de Detenidos y Desaparecidos por Razones Políticas, Liga
Argentina por los Derechos del Hombre (LADH), Madres de Plaza de
Mayo - Línea Fundadora, Movimiento Ecuménico por los Derechos
Humanos (MEDH), Servicio Paz y Justicia (SERPA). La mayoría de ellas,
excepto la LADH, se formaron preponderantemente entre los años política y técnico-administrativa de dicho gobierno en carácter de cogestores, funcionarios y/o empleados encargados de definir su contenido e implementar su institucionalización.

Algunos referentes de organizaciones de DD.HH. señalan que las múltiples actividades sociales vinculadas al

1975 y 1979 para exigir el reconocimiento de la violencia ejercida por el Estado y su reparación. Este movimiento incluye dirigentes de distintas congregaciones religiosas (como el caso del MEDH), diversas organizaciones de familiares de víctimas o afectados directos (como las Madres y Abuelas de Plaza de Mayo) y de profesionales del derecho (como el CELS). A estas organizaciones se las conoce como los "organismos históricos". Entre mediados de la década del ochenta e inicios del año 2000, se sumaron nuevas organizaciones de DD.HH. Ellas son, entre otras: Fundación Memoria Histórica y Social Argentina, Asociación de Ex Detenidos Desaparecidos (AEDD), H.I.J.O.S., Herman@s, Asociación Buena Memoria. Y se creó también una coalición de organismos denominada Memoria Abierta. 
repudio de los veinte años del golpe militar de 1976, sumadas a la nueva Constitución de la Ciudad (1996) y la elección de legisladores calificados por ellos como "comprometidos con la lucha de los organismos", abrieron un nuevo marco de posibilidades a nivel local. Sobre todo les permitió desarrollar un novedoso modelo de trabajo, definido como de "participación mixta" o "gestión compartida" entre agencias gubernamentales y organizaciones de la sociedad civil. A través de este proceso de trabajo conjunto, integrantes de organismos y políticos inscribieron la categoría "memoria sobre el terrorismo de Estado" en una serie de normas, agencias y programas gubernamentales.

Con relación a esta nueva modalidad de trabajo, nos preguntamos si la incorporación de militantes de DD.HH. al GCABA imprimió ciertas particularidades al proceso de institucionalización de la "memoria" como objeto de políticas públicas (relacionadas, por ejemplo, con la dinámica histórica del movimiento de DD.HH., caracterizado por su actividad de denuncia y demanda frente al Estado). Y, paralelamente, si la incorporación como cogestores, funcionarios y/o empleados ha repercutido en la representación de los propios integrantes de organizaciones de DD.HH. sobre su actividad político-militante.

Sin duda, la articulación entre autoridades gubernamentales e integrantes de organismos de DD.HH. no es un fenómeno reciente en Argentina. Tal como indica Emilio Crenzel (2008), la constitución de la Comisión Nacional sobre la Desaparición de Personas (CONADEP) y la elaboración del Informe "Nunca Más" (1984) fueron producto de una alianza tácita y un esfuerzo conjunto, que se tradujo en un proceso de legitimación recíproca entre la Comisión, los organismos, los sobrevivientes y los familiares, en el momento de la llamada "transición democrática". No obstante, frecuentemente, la relación entre las organizaciones de DD.HH. y el "Estado" (y/o el "Gobierno") tiende a ser concebida como contrapuesta o mutuamente excluyente; $y$, en el caso en que es reconocida de otro modo, generalmente se la califica como su anverso, es decir, se la describe en términos de cooptación de los organismos por parte del gobierno, o, se le imputa al gobierno la delegación de la responsabilidad pública que le compete a las agencias del Estado en las organizaciones de DD.HH. (Vezzetti, 2009). Sin embargo, otra perspectiva cobra relevancia cuando nos centramos en analizar las prácticas y representaciones de los propios integrantes de las organizaciones de DD.HH. y aquellos políticos que han participado conjuntamente en la instauración de una serie de leyes y agencias gubernamentales orientadas a "preservar y promover la memoria sobre el terrorismo de Estado" en el ámbito de la Ciudad Autónoma de Buenos Aires (CABA).

Respecto a los actores que han tenido un papel destacado en el proceso de institucionalización de la "memoria" como objeto de políticas públicas, vale aclarar que si bien realizamos una descripción de sus funciones y atribuciones, fundamentalmente nos interesa analizarlos en sus relaciones recíprocas y en sus interdependencias. Así, antes que proceder a una clasificación y descripción exhaustiva de los mismos, nos enfocamos en el análisis de sus prácticas y vinculaciones, indagando en el tipo de actividades privilegiadas por cada uno de ellos en pos de un mismo objetivo: "preservar y promover la memoria". En este sentido, a la manera de Víctor Turner (1980), retomamos determinados aspectos de los comportamientos que emergen en situaciones concretas, donde los actores se ven impulsados a tomar partido en términos de distintos imperativos, y a dar cuenta de sus posiciones e intereses más claramente. Esto nos ha permitido reconstruir, de modo semejante a cómo lo ha hecho Julian Pitt-Rivers (1971), escalas de obligaciones y preferencias por parte de los militantes de DD.HH., políticos y empleados del GCABA, con relación al trabajo desplegado para "preservar y promover la memoria sobre el terrorismo de Estado". A continuación, a partir de una descripción analítica, nos interesa dar cuenta de qué manera, a lo largo de más de una década, militantes de DD.HH., políticos y empleados del GCABA, han ido configurando no sólo el contenido cognitivo sino también performativo de la categoría "memoria sobre el terrorismo de Estado", inscribiéndola como objeto de políticas públicas de DD.HH., y convocándola institucionalmente a través de múltiples actividades en el ámbito de la Ciudad.

\section{La Comisión pro monumento a las víctimas del terrorismo de Estado: una novedosa experiencia de cogestión}

Desde 1996 en adelante, el Poder Legislativo de la Ciudad sancionó una serie de resoluciones, declaraciones, decretos y leyes tendientes a promover el recuerdo colectivo sobre la violencia política pasada en términos de "memoria de la dictadura" o "memoria sobre el terrorismo de Estado". Estas normativas establecieron, entre otras cosas, la señalización de los lugares que funcionaron como centros clandestinos de detención (CCD) y declararon la intención de convertir algunos de ellos en "Museos de la Memoria" (como el "Olimpo" y la "ESMA"), fijaron el "24 de marzo" como un día para trabajar en el ámbito escolar lo sucedido durante la Dictadura (1976-1983), y dispusieron la creación de parques, plazas y placas recordatorias en homenaje a los desaparecidos. Uno de los proyectos de ley de mayor envergadura fue el que estipuló la construcción de un Monumento a las víctimas del terrorismo de Estado y un Parque de la Memoria, ubicados en la costanera del Río de la Plata (Ley N 46/98).

Paralelamente, numerosos integrantes de organismos de DD.HH. se incorporaron a la nueva estructura político- 
administrativa del GCABA como actores acreditados gubernamentalmente para precisar el contenido de estas normativas y modelar la realización de obras materiales conmemorativas de gran envergadura a través de la constitución de nuevos órganos de gestión mixta, como la Comisión pro monumento a las víctimas del terrorismo de Estado (CPM), la Comisión de Trabajo y Consenso (CTyC) del CCD "Club Atlético", y el Instituto Espacio para la Memoria (IEM). Ente las agencias gubernamentales que incorporaron a la "memoria" como objeto de trabajo, podemos mencionar a la Dirección General de Derechos Humanos (DGDH), creada en el año 2000, promovida a fines de 2003 al rango de Subsecretaría de DD.HH. (SSDH), y la posterior Unidad Ejecutora de Proyectos de Sitios de Memoria (UEPSM), creada en el 2006, todas ellas dependientes de la Jefatura de Gabinete del GCABA.

A partir del proyecto del Parque y el Monumento, integrantes de los organismos históricos y militantes de nuevas organizaciones de DD.HH., como Buena Memoria, comenzaron a trabajar a la par con legisladores y funcionarios del GCABA, ya no exclusivamente en la elaboración de leyes (es decir, en el dominio jurídicopolítico) sino en el diseño y gestión de proyectos conmemorativos en el espacio urbano. Este trabajo implicó la articulación con representantes de distintos bloques partidarios, autoridades gubernamentales y trabajadores de diferentes áreas del GCABA que, en muchos casos, no estaban acostumbrados a interactuar periódicamente con activistas de DD.HH.

Los impulsores del Parque y el Monumento afirman que, en el momento en que presentaron este proyecto ante la Legislatura (1997), "era una novedad que un grupo de señoras con los pañuelos" fuera a reunirse con autoridades gubernamentales (como el Jefe de Gobierno, Fernando De la Rúa), o de otras institucionales estatales (como la Universidad de Buenos Aires), para plantearles la realización conjunta de obras materiales. Sin duda, estas novedosas reuniones tuvieron efecto. En 1998, por ejemplo, informados por las autoridades del GCABA de las futuras obras públicas a realizarse en la zona aledaña a la costanera norte del Río de la Plata, un grupo de referentes de organismos de DD.HH. y legisladores porteños se reunió con el Decano de Facultad de Arquitectura y Urbanismo, solicitándole la inclusión del proyecto del Parque en las bases del "Concurso de Ideas para el Desarrollo del Área Ciudad Universitaria de la Ciudad de Buenos Aires". Como corolario de las reuniones sostenidas entre integrantes de organizaciones de DD.HH., autoridades de la Facultad y políticos, la Universidad de Buenos Aires (UBA) y el GCABA firmaron un convenio que incluyó el proyecto del Parque en las bases del Concurso de Ideas, que se iba a ocupar de seleccionar propuestas para el desarrollo del área Ciudad Universitaria.

Tal vez la novedad referida por los militantes de DD.HH. respecto al proceso político en torno al desarrollo del proyecto del Parque y el Monumento, se explique porque los interlocutores privilegiados históricamente por los organismos de DD.HH. han sido las autoridades del Gobierno Nacional, a quienes sistemáticamente les han demandado la investigación sobre los crímenes de regímenes pasados y el juzgamiento de sus responsables, además de la vigencia de los DD.HH. en la actualidad. $Y$, a su vez, porque desde el dictado de las llamadas "leyes de impunidad", los "indultos a los represores" y la política de "reparación económica a las víctimas del terrorismo de Estado", algunos de ellos han mantenido una actitud de desconfianza frente a los sucesivos gobiernos, o, directamente, han adoptado una posición de confrontación respecto al Estado (generalmente representado como una entidad compacta y uniforme, "cómplice de la Dictadura" y/o "garante de la impunidad"). Al respecto, cabe destacar que algunos organismos (la Asociación Madres de Plaza de Mayo, la AEDD e H.I.J.O.S.) manifestaron su total desacuerdo con el proyecto del Parque y el Monumento, al que describieron como un "cementerio", que sólo serviría para "enterrar los ideales de los militantes revolucionarios" y "para que los políticos lavaran sus caras".

Más allá de la oposición radical de estas tres organizaciones de DD.HH. frente a la elaboración de proyectos junto al GCABA, lo cierto es que la mayoría de los organismos se involucró con legisladores y funcionarios en la realización del proyecto del Parque y el Monumento, y otras muchas iniciativas públicas de carácter conmemorativo en el ámbito urbano. Esta alianza estratégica implicó la participación periódica en numerosas reuniones y actividades conjuntas tendientes a diseñar y plasmar proyectos comunes en materia de "memoria sobre el terrorismo de Estado". Representantes de organismos de DD.HH. y políticos del GCABA refieren que la creación de ámbitos de trabajo compartido fue una experiencia política meritoria, donde todos los participantes enriquecieron sus propias perspectivas y consolidaron su compromiso mutuo, a través de la elaboración de proyectos cuyo contenido fue convenido por consenso.

La CPM, de hecho, asumió características sui generis respecto a las Comisiones instauradas por la Legislatura porteña, las que están directamente ligadas a su funcionamiento político. A diferencia de las comisiones legislativas permanentes (compuestas por diputados y asesores), encargadas de evaluar los proyectos de ley y asesorar a los diputados en las temáticas sobre las que dictaminan, o, las comisiones especiales, encargadas de auditar la aplicación de leyes por parte del Poder Ejecutivo de la Ciudad, la CPM fue creada con una misión ejecutiva (el diseño y construcción del Parque y el Monumento) y fue constituida como un órgano cuatripartito, integrado por el Poder Ejecutivo, el Poder Legislativo, la UBA y diez organizaciones de DD.HH.: Abuelas de Plaza de Mayo, APDH, Buena Memoria, CELS, Familiares, Fundación Memoria Histórica y Social Argentina, LADH, Madres de 
Plaza de Mayo - Línea Fundadora, MEDH y SERPAJ.

Formalmente, la primera ordenación de la CPM fue presidida por el Vicepresidente $1^{\circ}$ de la Legislatura, Aníbal Ibarra, y una Mesa Coordinadora integrada por diputados de los distintos bloques partidarios y dos integrantes de organismos de DD.HH. Sus tareas fundamentales fueron: en primer lugar, la participación en el diseño referente a la realización del Monumento; en segundo lugar, la organización de un concurso internacional de esculturas para elegir cuáles serían emplazadas en el Parque de la Memoria; y, en tercer lugar, la elaboración de la "nómina de desaparecidos y asesinados por el terrorismo de estado" que se emplazaría en dicho Monumento (Ley 46/98, Art. $4^{\circ}$ y $5^{\circ}$ ).

De acuerdo a la perspectiva de los organismos, cada uno de los actores representados en la CPM ocupaba un rol definido en la división del trabajo para llevar adelante las misiones orientadas a crear el Parque y el Monumento. Las organizaciones de DD.HH. eran las encargadas de pautar el sentido de las tareas encomendadas a la CPM, según el consenso alcanzado previamente entre ellas en reuniones independientes de los representantes del GCABA. El Poder Ejecutivo, por su parte, era el encargado de realizar las acciones necesarias para alcanzar lo que los organismos definieran, y el Poder Legislativo aportaba la pluralidad de opiniones políticas presentes en la sociedad, y vigilaba la asignación de personal y presupuesto para plasmarlas. Por último, la UBA proveía el terreno y la propuesta arquitectónica para la construcción del Parque y el Monumento. Sin embargo, no todos los actores compartían esta idea sobre la división del trabajo postulada por los representantes de organizaciones de DD.HH. En este sentido, creemos que el rol de ciertas personalidades sociales, ubicadas en una posición clave en la articulación entre los diferentes actores que conformaron la CPM, fue fundamental para adecuar la estructura político-administrativa del GCABA a los parámetros ideales de trabajo pautados por los organismos.

Al crearse formalmente la CPM y comenzar las reuniones periódicas entre legisladores, funcionarios, y representantes de organizaciones de DD.HH. (realizadas en la Legislatura), surgió la necesidad operativa de nombrar a un Coordinador, encargado de convocar a los distintos grupos y sus representantes, tomar actas de las reuniones, elaborar y distribuir las minutas, y concertar el trabajo de las distintas áreas del GCABA encargadas de plasmar los objetivos de la CPM. La persona designada para asumir el cargo de Coordinadora de la CPM fue una de las militantes de Buena Memoria, Gabriela Alegre. El fundamento de su nombramiento emanó sobre todo del reconocimiento otorgado por parte de referentes de organismos históricos de DD.HH. y algunos legisladores hacia su labor para crear interés en este proyecto, y su trayectoria política, de algún modo análoga a la de otros representantes de organizaciones de DD.HH. y legisladores del GCABA, ya sea por su formación en el Colegio Nacional de Buenos Aires (como el Vicepresidente de la Legislatura), la militancia estudiantil en la Unión de Estudiantes Secundarios (UES), el exilio en Brasil y su participación en Buena Memoria. En pocas palabras, los integrantes de la CPM expresaron el reconocimiento a su capacidad político-militante, que permitió transformar el anhelo de algunos organismos de DD.HH. en un proyecto del gobierno local, a través de la articulación del mundo de sus relaciones personales con el tejido institucional del GCABA.

Sin dudas, más allá del reconocimiento mutuo otorgado por los legisladores al proyecto de los organismos para realizar el Parque y el Monumento, y de los referentes de los organismos a los legisladores, todas las obras materiales e inmateriales que él ha implicado, no hubieran sido posibles sin la asignación de recursos públicos (económicos y humanos), y la asistencia de las áreas ejecutivas del GCABA, garantizada por sus autoridades. En este sentido, un hecho clave que signó el trabajo para llevar a cabo las tareas estipuladas por la CPM, fue la elección del Vicepresidente de la Legislatura como Jefe de Gobierno de la Ciudad, y el nombramiento de la Coordinadora de la CPM como Directora General de DD.HH.

A partir del año 2000, la DGDH pasó a ser el organismo gubernamental encargado de concertar y supervisar el trabajo de las demás áreas de gobierno involucradas en la realización del Parque y el Monumento. Dada la imposibilidad de asignar presupuesto propio a la CPM, la DGDH también se ocupó de contratar el personal requerido para desempeñar las tareas administrativas, pedagógicas, investigativas, y de curaduría artística requeridas por dicha Comisión. Una misma persona ejerció, paralelamente, el cargo de Coordinadora de la CPM, en el ámbito del Poder Legislativo, y de Directora General de DD.HH., en el ámbito del Poder Ejecutivo. La hibridación de ambos cargos políticos en una misma persona, como ampliaremos más adelante, habilitó un desarrollo personalizado de los proyectos de memoria en el GCABA, debido a su coordinación continuada por casi una década. Además, fomentó la articulación de relaciones de confianza mutua entre representantes de organismos de DD.HH. con funcionarios del GCABA, sustentadas en el trabajo conjunto a lo largo de varios años. Y, a su vez, incidió en las características del personal contratado para llevar adelante el trabajo en la CPM y la DGDH, a partir del criterio de selección utilizado, ligado a la trayectoria político-militante de la CoordinadoraDirectora.

\section{La incorporación de la "memoria" como objeto de políticas públicas en la estructura del gobierno de la Ciudad}

Desde la promulgación de la Constitución de la Ciudad (1996), los sucesivos gobiernos han creado distintos 
órganos enfocados en garantizar la vigencia de los DD.HH. de sus ciudadanos, incorporando entre sus atribuciones la "preservación y promoción de la memoria sobre el terrorismo de Estado". Varios organismos han apoyado este tipo de iniciativas, elaborando y presentado proyectos de distinto tipo enfocados en el desarrollo de este objetivo en particular. Algunas de las razones citadas por ellos para articular su trabajo con representantes políticos del GCABA, como ya hemos mencionado, han sido: la presencia de políticos "receptivos" a sus demandas; la existencia previa de proyectos gubernamentales para crear algún tipo de obra pública y/o institución para evocar a los desaparecidos y reflexionar colectivamente sobre el terrorismo de Estado (como el "Museo de la Memoria" en el ex CCD "Olimpo" y/o "ESMA"); y la presencia de un amplio movimiento social que activó la demanda de "Memoria, Verdad y Justicia" en el espacio urbano, a través de la realización de homenajes puntuales a los desaparecidos (en sus barrios, lugares de estudio y/o trabajo) y movilizaciones masivas (como las del 24 de marzo, desde la Plaza de los dos Congresos hasta la Plaza de Mayo).

Integrantes de algunas organizaciones de DD.HH. promovieron que la participación conjunta con algunos políticos del GCABA permitiría producir cambios sociales a largo plazo, a través de la elaboración de instituciones y obras conmemorativas perdurables en el dominio público. Uno de los objetivos, en este sentido, era lograr que el Estado afirmara públicamente que "la verdad y la justicia son las premisas a partir de las cuáles reflexionar sobre el terrorismo de Estado, reconociendo el pasado como parte de la identidad generacional e institucional en el presente" (CELS, 1999). Con base en este objetivo de máxima, fundamentaron que "preservar y promover la memoria sobre el terrorismo de Estado" era una herramienta política insoslayable para forjar la "conciencia histórica de los argentinos" y un deber político para asegurar el "orden institucional democrático". Este objetivo fue incorporado e implementado a través de la creación de agencias gubernamentales que adoptaron características particulares en cuanto a la composición de su dirección político-administrativa, sustentadas en la experiencia pionera de gestión mixta de la CPM.

Durante el mandato del primer Jefe de Gobierno de la Ciudad Autónoma de Buenos Aires, Fernando de la Rúa (1996-1999), el tópico "derechos humanos" fue incorporado dentro del organigrama de la nueva estructura político-administrativa como objeto de una Comisión, dependiente de la Secretaría de Cultura. Esta Comisión de DD.HH. contó con una mínima estructura material (patrimonio, presupuesto y recursos humanos), y no tuvo demasiadas atribuciones asignadas. Los proyectos vinculados a la "memoria sobre el terrorismo de Estado", en ese entonces, no eran mencionados ni en la guía de servicios del GCABA, ni en la guía más específica elaborada en 1999 por la Comisión de DD.HH. Este tipo de proyectos se consolidó, más bien, en el ámbito de la Legislatura, donde los integrantes de las organizaciones de DD.HH. contaron con el apoyo político de numerosos legisladores, pertenecientes a diferentes bloques partidarios; y dónde los propios legisladores ya habían elaborado declaraciones, resoluciones y leyes tendientes a este mismo objetivo.

En el año 2000, el Vicepresidente $1^{\circ}$ de la Legislatura y Presidente de la CPM, Aníbal Ibarra, fue electo Jefe de Gobierno de la Ciudad. Una de sus primeras actividades fue la definición del Gabinete y el organigrama políticoadministrativo. En materia de DD.HH, disolvió la anterior Comisión de DD.HH. y, a cambio, creó la Dirección General de Derechos Humanos (DGDH). La DGDH amplió notablemente las tareas en materia de DD.HH. realizadas por la Comisión anterior, e incorporó numerosas actividades tendientes a "preservar y promover la memoria sobre el terrorismo de Estado", guiándose por las leyes sancionadas por la Legislatura respecto a este objetivo ${ }^{2}$. La "promoción de la memoria" fue uno de los objetivos centrales estipulados por ella. Una de las actividades privilegiadas por su Directora consistió en investigar los "crímenes cometidos por el Estado argentino durante los años '70 y '80", para "dar a conocer la verdad y evitar que se repitan", a través del fortalecimiento institucional de su reconocimiento público. Tal objetivo, sin embargo, no se redujo únicamente a difundir información sobre los "crímenes del terrorismo de Estado", sino también sobre otros crímenes catalogados como de lesa humanidad, como: el "genocidio armenio", el "atentado contra la AMIA", y el "Holocausto judío"3.

Desde el año 2000, progresivamente, el GCABA creó e implementó una serie de programas educativos, culturales y de DD.HH. destinados a "construir memoria del terrorismo de Estado". A través de múltiples actividades,

\footnotetext{
2 Por ejemplo, se ocupó de aplicar la Ley $N^{\circ} 355$, aprobada por la Legislatura el 23 de marzo de 2000, que declaró el 24 de marzo de cada año como el "Día de la memoria en homenaje a todas las personas que sufrieron persecuciones, encarcelamientos, torturas, muerte o desaparición durante la represión llevada a cabo por el terrorismo de Estado" (Art. $1^{\circ}$ ). Y dictaminó la inclusión del 24 de marzo "en el calendario escolar de los distintos niveles el dictado de clases alusivas a los golpes de estado y a la consecuente ruptura del orden constitucional y la violación de los Derechos Humanos, fortaleciendo los valores del sistema democrático y sus instituciones" (Art. $3^{\circ}$ ).

3 La DGDH elaboró una serie de cuadernillos pedagógicos, bajo el título "Educación para la Memoria", editados y distribuidos gratuitamente, ellos fueron los siguientes: "4 de julio de $1976-4$ de julio de 2001, 25 años de la masacre de San Patricio"; "Memoria por la justicia. Apuntes y actividades para trabajar sobre el atentado a la sede de la AMIA", realizado junto a Familiares y amigos de las víctimas de la masacre en la AMIA, AMIA Comunidad Judía y el Consejo de Educación Judía de la República Argentina; "19 de abril, Día de la Convivencia en la Diversidad Cultural", realizado junto a Fundación Memoria del Holocausto - Museo de la Shoa; "Genocidio negado. Genocidio Armenio", realizado junto al Consejo Nacional Armenio de Sudamérica; y "Recuerdo, reflexión y aprendizaje. Apuntes y actividades para trabajar sobre el Día de la Memoria", realizado junto a la Secretaría de Educación.
} 
la "memoria" fue promovida institucionalmente como un "derecho" y un "deber cívico" y como un "legado intergeneracional", representado como garantía preventiva respecto a posibles violaciones a los derechos humanos y/o la interrupción del "orden constitucional".

Para ese entonces, en el ámbito del GCABA también se estaba discutiendo el destino del predio donde funcionó el CCD "ESMA" como "Museo de la Memoria". Y, organizaciones sociales, partidos políticos de izquierda, organismos de DD.HH., familiares de detenidosdesaparecidos y sobrevivientes, venían demandando al GCABA el señalamiento público de los CCD y el desalojo de sus propietarios con el objetivo de convertirlos en "museos" o "sitios de memoria". Por ejemplo, en 2002 fueron descubiertos los restos materiales del CDD "Club Atlético", derruido y sepultado cuando fue construida la Autopista Buenos Aires - La Plata. Sobrevivientes de dicho lugar, junto a familiares de detenidos-desaparecidos, integrantes de organismos de DD.HH. y organizaciones barriales, habían presentado un proyecto al legislador Abel Fatala (FREPASO, 1997-1999), vecino del lugar, quien al ser nombrado Secretario de Obras y Servicios Públicos por el Jefe de Gobierno, facilitó la excavación que permitió encontrar los restos del ex CCD, con el asesoramiento de un grupo de arqueólogos, antropólogos y arquitectos contratados por la DGDH. En abril de 2002, comenzaron las obras que se constituyeron en la primera iniciativa de arqueología urbana relacionada con la memoria de los crímenes cometidos por el terrorismo de Estado en la Ciudad. La Directora de la DGDH manifestó ante la prensa su preocupación personal e institucional (como ex militante, compañera y funcionaria del GCABA) sobre qué hacer ahora para que ese lugar se convirtiera en un "sitio de memoria", presentándolo como un "deber político":

"El objetivo es el rescate arqueológico de los cimientos y chequear su estado de conservación. Ahora debemos pensar en cómo vamos a transformarlo en un sitio para la memoria... Yo fui de esa generación, tuve amigos ahí adentro. Y por supuesto que creo que esta tarea debía haberse hecho hace muchos años, cuando todavía podía servir como prueba y testimonio de la Justicia, pero no se hizo. Y mi deber como funcionaria es hacerlo ahora..." (Clarín, 8 de mayo de 2002).

Como corolario del trabajo conjunto entre sobrevivientes, familiares de desaparecidos, militantes de DD.HH. y de organizaciones barriales, y funcionarios y empleados del GCABA, en el año 2003, el Jefe de Gobierno elaboró el Decreto $N^{\circ}$ 219/03, por el cual creó el "Programa para la recuperación de la memoria del CCD Club Atlético" en la órbita de la DGDH. Este Programa le otorgó un marco institucional al trabajo que ya venían realizando distintos actores con el objetivo de constatar la existencia del CCD y transformar el lugar en un "sitio de memoria". El Decreto estipuló la conformación de una Comisión de Trabajo y Consenso (CTyC), encargada de diseñar los objetivos y lineamientos generales del Programa, y de una Unidad Ejecutora (UE), encargada de coordinar y evaluar las acciones destinadas a su realización efectiva. La CTyC fue integrada por representantes de organismos de DD.HH. y de organizaciones barriales, familiares de detenidos-desaparecidos, sobrevivientes del CCD y la DGDH. La UE fue integrada por cuatro representantes de la CTyC y los funcionarios de las áreas del Gobierno con responsabilidad en el proyecto.

Además de ocuparse de estas múltiples iniciativas, la Directora General de DD.HH. continuó coordinando las tareas de la CPM. Respecto a dicha Comisión, si bien ella dependía institucionalmente de la Legislatura y funcionaba en su edificio, sus integrantes preveían que, una vez cumplidas la misión para las que fue creada (es decir, la realización del Parque y el Monumento), tendrían que crear otro órgano de gestión dentro de la estructura político-administrativa del Poder Ejecutivo. Pues, si bien la CPM se había radicado originalmente en la Legislatura, debido a la existencia de numerosos legisladores "comprometidos con la causa de los DD.HH.", ese no era su ámbito de funcionamiento "natural". De hecho, la Ley N 46/98 establecía lo siguiente: "La Comisión concluirá sus actividades tres meses después de la inauguración definitiva del paseo" (Art. $\left.7^{\circ}\right)$. En este sentido, la Coordinadora de la CPM comenzó a trabajar, junto a representantes de organismos de DD.HH. y algunos políticos, en el diseño de un nuevo órgano de gestión que contemplara las tareas que demandaría la obra ya culminada, y que permitiera asegurar la dirección política por parte de los organismos de DD.HH., no sólo para este proyecto, sino para todos los otros que se estaban llevando adelante en la Ciudad con el objetivo de "preservar y promover la memoria sobre el terrorismo de Estado". Como corolario de estas reuniones entre representantes de organismos de DD.HH. y políticos, surgió la propuesta de crear un Instituto y/o Espacio para la Memoria (IEM) que coordinara las diversas iniciativas conmemorativas existentes y venideras, centralizando el trabajo de las distintas áreas del Gobierno.

El interés por crear un órgano que centralizara los proyectos para "preservar y promover la memoria" concernía a varios organismos de DD.HH., pero no todos compartían la misma posición respecto a la articulación con el Estado y con los sucesivos gobiernos. De hecho, varios organismos se nuclearon en un principio en Memoria Abierta con la finalidad de coordinar sus acciones para sostener una "posición propia frente al Estado" y pautar su liderazgo en las iniciativas públicas tendientes a "preservar y promover la memoria sobre el terrorismo de Estado". La principal inquietud por parte de los representantes de las organizaciones de DD.HH. respecto a la creación del IEM radicaba en poder garantizar el control de su dirección política y económica para poder llevar adelante sus propias propuestas en 
materia de DD.HH. y memoria. Los organismos, entonces, realizaron reuniones independientes de los políticos del GCABA para acordar entre ellos una posición consensuada sobre las características que debía tener este nuevo órgano de gestión para que ellos la aceptaran. En este sentido, demandaron la representación mayoritaria de los organismos de DD.HH. en su Directorio y que la financiación público-privada fuera administrada y auditada por ellos.

En diciembre de 2002, la Legislatura aprobó la Ley $N^{\circ}$ 961/02, que creó el IEM como un “Ente autárquico en lo económico financiero y autónomo en los temas de su incumbencia" (Art. $1^{\circ}$ ). Su misión consistió en "el resguardo y la transmisión de la memoria e historia de los hechos ocurridos durante el terrorismo de Estado, de los años '70 y '80 hasta la recuperación del estado de Derecho, así como los antecedentes, etapas posteriores y consecuencias, con el objeto de promover la profundización del sistema democrático, la consolidación de los derechos humanos y la prevalencia de los valores de la vida, la libertad y la dignidad humana" (Art. $2^{\circ}$ ). Entre las funciones atribuidas para cumplir con dicha misión general, la Ley N 961/02 convino: "Recopilar, sistematizar y conservar el material documental y testimonial correspondientes a la época pertinente, el que pasará a integrar el acervo patrimonial del IEM"; "realizar exhibiciones o muestras, eventos de difusión y de concientización sobre el valor de los derechos humanos vulnerados durante la etapa del terrorismo de Estado, sus consecuencias y la reafirmación del Nunca Más". Otra de las atribuciones previstas consistió en: "Recuperar los predios o lugares en la Ciudad donde hubieran funcionado Centros Clandestinos de Detención o hubieran ocurrido otros acontecimientos emblemáticos de la época, promoviendo su integración a la memoria urbana", e "Integrar a su plan de trabajo las actividades que la Comisión Pro Monumento a las Víctimas del Terrorismo de Estado le derive para su realización y sea aceptado por el IEM" (Art. $3^{\circ}$ ). La misión general y atribuciones específicas del IEM subsumieron gran parte de las actividades que ya venían desarrollando otras agencias gubernamentales, como la DGDH, y entidades no gubernamentales de DD.HH., como Memoria Abierta. Por esta misma razón, la Ley N 961/02 estipuló, a su vez: "Promover redes de información con otros centros, institutos o dependencias estatales o no, sean nacionales, provinciales o internacionales, académicas o sitios digitales que tuvieren intereses comunes o realizaran actividades complementarias con su misión y función en la Ciudad" (Art. $3^{\circ}$ ).

Luego de que la Ley $N^{\circ}$ 961/02 fue aprobada por la Legislatura, los representantes de los mismos organismos de DD.HH. que integraban la CPM continuaron trabajando junto a políticos del GCABA en la elaboración de un decreto de reglamentación, para regular la designación de sus autoridades y el funcionamiento general. En el año 2003, fue aprobado el Decreto $N^{\circ} 835 / 03$, que ubicó al Instituto "Espacio para la Memoria" en el área de mayor jerarquía en materia de DD.HH. dentro de la estructura del GCABA. Y dictaminó el llamado para la creación del Consejo Directivo (CD) del IEM, integrado por representantes de las mismas diez organizaciones de DD.HH. que integran la CPM; cinco funcionarios del Poder Ejecutivo, en representación de las áreas cuyas responsabilidades primarias contribuyan al desarrollo de la misión y función del IEM (designados por el Jefe de Gobierno); cinco diputados titulares y cinco suplentes (designados por el Poder Legislativo); y seis "personalidades con reconocido compromiso en la defensa de los Derechos Humanos" (elegidos por los miembros nombrados con anterioridad). El Jefe de Gobierno sería el encargado de designar al Director/a Ejecutivo/a y al Secretario/a Ejecutivo/a, según el resultado elevado por un jurado, previo concurso de antecedentes elaborado por el CD. El concurso de antecedentes, según lo establecido en el Decreto, debía tener en cuenta "la idoneidad técnica, los antecedentes profesionales y laborales y, especialmente, los valores éticos e intelectuales demostrados particularmente en el campo de los derechos humanos y en el marco institucional de la democracia" (Art. $5^{\circ}$ ). La Directora elegida por los integrantes del CD fue Ana María Careaga, una de las primeras integrantes de la CTyC del "Club Atlético", periodista, sobreviviente de dicho CCD, exiliada e hija de la una de las fundadoras de las Madres de Plaza de Mayo.

Un hecho clave que derivó en la reestructuración del área de DD.HH. del GCABA fue la "tragedia de Cromañón", ocurrida el 30 de diciembre de 2004. A raíz de este evento el panorama de trabajo de la SSDH fue modificado abruptamente. La mayoría de los empleados fueron exceptuados de sus tareas habituales y puestos a disposición para hacer guardia en la Morgue Judicial, recibir denuncias sobre personas desaparecidas, garantizar asistencia médica y, posteriormente, sistematizar los datos de cada uno de los afectados, los que fueron cargados en una base de datos especialmente diseñada para ello. Una de las consecuencias de este evento, y el proceso político y judicial que le siguió con el objeto de identificar a los responsables, fue la destitución del Jefe de Gobierno, Aníbal Ibarra, por medio de un "Juicio Político" realizado en marzo de 2006 . En su lugar asumió el Vicejefe de Gobierno, Jorge Telerman (2006-2007).

El nuevo Jefe de Gobierno dispuso una reforma administrativa a través de la llamada "Ley de Ministerios" (Ley $\left.N^{\circ} 1.925 / 06\right)$ por la cual se crearon once ministerios, entre ellos: el Ministerio de DD.HH. y Sociales (MDHS), encabezado por Gabriela Cerruti, periodista, ex Directora Ejecutiva de la "Comisión Provincial por la Memoria" y actual legisladora. El nuevo Ministerio, unificó la Secretaría de Desarrollo Social con la SSDH. De acuerdo a la Ministra, "la decisión de crear la nueva estructura no tuvo sólo razones de funcionamiento sino que fue claramente 
conceptual, y ligada a una visión moderna y abarcadora de los derechos humanos, económicos y sociales"4. A partir de esta conceptualización, redimensionó los programas encargados de "preservar y promover la memoria" dentro del vasto campo de los DD.HH.

Con el cambio de Jefe de Gobierno, y la creación del Ministerio de DD.HH. y Sociales, Gabriela Alegre fue desplazada del cargo de Subsecretaria de DD.HH., y en su lugar fue nombrada la abogada del CELS, María José Guembe. Ante esta decisión, varias organizaciones de DD.HH. se presentaron directamente ante Jorge Telerman para solicitarle la permanencia de Alegre y exigirle la continuidad de los programas gubernamentales destinados a "preservar y promover la memoria sorbe el terrorismo de Estado". El pedido de referentes de organismos tuvo como efecto que la ex Subsecretaria de DD.HH. fuera designada como Coordinadora de una nueva agencia gubernamental, denominada: Unidad Ejecutora de Proyectos sobre Sitios de Memoria (UEPSM). Su función fue limitada a la gestión de la CPM, los "programas para la recuperación de la memoria histórica" sobre los ex CCD "Club Atlético" y "Olimpo", y los trámites relativos a la expropiación de los edificios donde funcionaron los ex CCD "Virrey Ceballos" y "Automotores Orletti".

El cambio político-administrativo en el GCABA, y la tensión generada entre los funcionarios desplazados y la nueva gestión política designada en el área de DD.HH., se puso de manifiesto en una serie de acusaciones cruzadas, publicitadas a través de la prensa, entre políticos (caracterizados como telermanistas vs. Ibarristas), entre funcionarios y representantes de organismos de DD. HH. (Ministra de DDHH. y Sociales vs. Presidenta de Abuelas de Plaza de Mayo), y entre los propios referentes de algunos organismos de DD.HH. (como Abuelas vs. CELS). El reacomodamiento político-administrativo tuvo como correlato un cambio en la posición de los organismos de $\mathrm{DD} . \mathrm{HH}$. respecto a la relación con los funcionarios del GCABA. La relación de confianza establecida a lo largo de varios años de trabajo conjunto con funcionarios reconocidos como "comprometidos con la cusa de los DD.HH." fue puesta en consideración. Por ejemplo, en agosto de 2006, tras el pedido de renuncia a la Coordinadora de la UEPSM, varios organismos de DD.HH. (Abuelas, APDH, Familiares, H.I.J.O.S. Regional Capital, y Madres de Plaza de Mayo - Línea Fundadora) volvieron a interceder en su defensa, dando una conferencia de prensa donde afirmaron su respaldo en "reconocimiento a su trayectoria política, moral y ética". A su vez, las organizaciones de DD.HH. representadas en la CPM protestaron (a excepción del CELS) por las demoras en la culminación de las obras del Monumento, pintando los nombres de desaparecidos y asesinados en la base de cemento sobre la que se colocarían las placas de pórfido. Los integrantes de la CPM declararon públicamente que

\footnotetext{
${ }^{4}$ Cf. http://www.gabicerruti.com.ar/ar/ministra [Consulta: 23 de Octubre de 2010]
}

el gobierno de Jorge Telerman no tenía "un compromiso político con respecto a la memoria del Terrorismo de Estado" y responsabilizaron a su gestión política de "obstaculizar el desarrollo de las políticas de memoria a través de diversas medidas".

Los cambios en la estructura político-administrativa, y la renuncia de la Coordinadora de la UEPSM, abrieron un fuerte debate al interior de las organizaciones de DD.HH. vinculadas a la gestión de distintos "proyectos de memoria" junto al GCABA. Este debate giró en torno al dilema de si lo prioritario era "defender funcionarios" o "defender políticas". Para algunos, la defensa de las políticas de DD.HH. incluía a los políticos que las habían implementado, pues además de "funcionarios", ellos eran reconocidos como "compañeros militantes", comprometidos personalmente con la "lucha de los organismos" y la realización efectiva de los "proyectos de memoria". Para otros, en cambio, justamente porque se trataba de políticas públicas, ellas debían ser concebidas independientemente de los actores que las implementaran, garantizando la continuidad de los programas gestionados por las distintas Comisiones de Trabajo, como las CTyC de los ex CCD "Club Atlético" y "Olimpo".

Los representantes de organismos involucrados en la gestión de proyectos de memoria junto a políticos del GCABA, desplegaron distintas representaciones sobre el Estado, ya sea caracterizándolo como una red de relaciones interpersonales articuladas con el tejido institucional, o como un conjunto de funciones administrativas impersonales descritas en términos ideales. Sin embargo, más allá del contenido semántico de tales representaciones, la apelación por parte de los distintos actores fue situacional. La tensión entre integrantes de organismos y funcionarios sobre las políticas de DD.HH., y más específicamente, sobre los programas para "preservar y promover la memoria sobre el terrorismo de Estado", se manifestó en términos de adhesiones personales más que en términos político-ideológicos. Las acusaciones cruzadas pusieron de manifiesto la constitución de una red de relaciones personales interjerárquicas, que excedía el estricto dominio político-administrativo gubernamental ampliándose al dominio de las relaciones sociales locales, especialmente entre representantes de organizaciones de DD.HH. y funcionarios del GCABA, sustentadas en el desarrollo de actividades conjuntas a lo largo de varios años y la exaltación de compromisos compartidos.

Luego de la disputada renuncia de la Coordinadora de la UEPSM, Margarita Jarque (abogada, ex diputada nacional por el Frente Grande, colaboradora de la Comisión Provincial por la Memoria de La Plata) fue nombrada en el cargo. Sin un amplio apoyo por parte de los organismos de DD.HH. locales, la nueva Coordinadora continuó básicamente con los programas heredados de la gestión política anterior. La nueva Coordinadora duró en el cargo 
aproximadamente un año, hasta la asunción del nuevo Jefe de Gobierno, Mauricio Macri, electo en el año 2007. Durante ese ciclo, se encargó de traspasar los programas que estaban bajo la órbita de la UEPSM a otras áreas competentes dentro del GCABA (como el IEM o la SSDH), de acuerdo a la petición de cada una de las Comisiones (CPM y CTyC de los ex CDD "Club Atlético" y "Olimpo"). El proyecto del Parque y el Monumento fue trasferido a la SSDH. Todos los demás programas radicados en la UEPSM fueron transferidos al IEM, con su personal, presupuesto y patrimonio.

La descripción analítica de la incorporación de la "memoria sobre el terrorismo de Estado" como objeto de políticas públicas de DD.HH. dentro del organigrama del GCABA, a través de las sucesivas transformaciones político-administrativas que tuvieron lugar entre los años 1996 a 2007, nos ha permitido registrar de qué manera la articulación y desarticulación de redes interpersonales entre representantes de organismos de DD.HH. y políticos ha incidido en la composición dinámica de dicho objeto. A la constitución de una Comisión de DD.HH. con mínimas atribuciones, que no incluyó ninguna actividad destinada a "preservar y promover la memoria sobre el terrorismo de Estado", le siguió la creación e implementación de programas gubernamentales culturales y educativos, la creación de proyectos conmemorativos y la diversificación de órganos de gestión política especializados en su administración y consolidación en el espacio urbano.

A lo largo de este proceso de institucionalización legislativa y consagración ejecutiva, edificado por medio del trabajo conjunto entre militantes de DD.HH., funcionarios y legisladores, se fundaron experiencias compartidas, vínculos afectivos (de amistad y enemistad), adhesiones políticas a ciertas personalidades y/o partidos, e incluso conocimientos especializados (forjados a través del propio debate sobre cada uno de los proyectos y el asesoramiento de profesionales nacionales e internacionales), que otorgaron ciertos parámetros colectivos en torno a cuál era la forma adecuada de llevar adelante y plasmar la "memoria" como objeto de políticas estatales de derechos humanos en la Ciudad de Buenos Aires.

La articulación entre militantes de DD.HH. y los políticos del GCABA no se reduce a la cooptación de los organismos por parte del "Estado", ni a la delegación de la responsabilidad de los representantes gubernamentales en las organizaciones de DD.HH. Más bien, la articulación entre ellos se ha caracterizado por la instauración de lazos de cooperación y la creación de instancias de cogestión en torno a un objetivo compartido: "preservar y promover la memoria sobre el terrorismo deEestado". El establecimiento de relaciones de cooperación entre militantes de DD.HH. y políticos del GCABA sostenidas en el tiempo, se ha caracterizado por el establecimiento de mecanismos de asociación y disociación, a través de la lógica del reconocimiento mutuo, expresada en términos de "compromiso", entendido como un valor moral y político. En este sentido, la apelación al "compromiso" ha operado como un factor de legitimación de la relación de cooperación mutua entre militantes de DD.HH. y políticos, y, al contrario, la falta de "compromiso" ha operado como explicación de la disociación de los lazos de cooperación entre los organismos de DD.HH. y el Gobierno. Con relación a este tipo de evaluación moral respecto a las relaciones de cooperación mutua, la designación de una militante de DD.HH. en una posición política interjerárquica clave, como la coordinación de la CPM y la dirección de la DGDH, coadyuvó al reconocimiento del compromiso como un componente clave de la realización de los proyectos de memoria y, a la vez, fortaleció su posición al operar a modo de traductor entre los organismos de DD.HH., evaluando la relación entre ellos en tales términos. Paradójicamente, si pensáramos la articulación entre estos actores en términos de cooptación, sería más acertado hablar de cooptación del "Estado" por parte de los organismos de DD.HH. que a la inversa, pues fueron los miembros de un organismo colegiado como la CPM los que eligieron a una militante de DD.HH. para ocupar ambos cargos de autoridad política.

La relación entre militantes de DD.HH. y políticos en torno a "preservar y promover la memoria", y los efectos de consagración de esta relación a través de obras materiales comunes, se han expresado a través del compromiso. Para los propios actores, sin este componente, tanto la propia relación así como las obras pierden su sentido. Compromiso con la "democracia", los "derechos humanos", el "Nunca Más", la "lucha de los organismos", "Memoria, Verdad y Justicia". El compromiso asumido en la producción activa de las valores morales, considerados condiciones fundantes de la sociedad y sus instituciones políticas, a través de la consolidación de la solidaridad social. A continuación, nos interesa analizar cómo esta cualidad se ha expresado a través del "trabajo por la memoria" en el GCABA, representado y fomentado como una actividad con características particulares.

\section{El "trabajo por la memoria": técnica y mística}

A partir del relevamiento y análisis de las actividades desarrolladas en la CPM, la DGDH, la SSDH y la UEPSM (2000-2006), podemos identificar dos componentes que se presentaron como constitutivos de las tareas desarrolladas habitualmente por sus empleados, a las que denominaremos: "técnica" y "mística". Toda actividad laboral asignada y asumida por ellos implicaba algún tipo de capacidad técnica específica (según la tarea puntual asignada) pero, al mismo tiempo, suponía una actitud comprometida con la misión general del órgano de gestión. La apelación al "compromiso", como expondremos más adelante, se puso manifiesto explícitamente en ciertas situaciones o eventos coyunturales (como la organización 
de la marcha de cada 24 de marzo), pero actuó permanentemente de un modo tácito en el desempeño de toda una serie de actividades suplementarias al rol asignado en el contrato laboral, superponiéndose a las tareas administrativas o técnicas, estipuladas de acuerdo a los objetivos específicos de cada programa, planificados anualmente por el coordinador o director de cada una de las agencias gubernamentales (CPM, DGDH, SSDH, UEPSM).

El reclutamiento de los empleados en estas órganos gubernamentales, de algún modo, también respondió a estos dos componentes (pericia técnica y compromiso), expresados en dos criterios de selección distintos, pero no excluyentes: la formación profesional y la trayectoria militante. De acuerdo estos criterios, los directivos de las agencias gubernamentales orientadas a la "preservación y promoción de la memoria" incorporaron profesionales provenientes de diferentes disciplinas académicas y especialidades técnicas (abogados, antropólogos, arquitectos, diseñadores gráficos, licenciados en arte, trabajadores sociales, periodistas) para encargarse de las tareas específicas de cada área, y militantes de DD.HH. (sobre todo integrantes de Buena Memoria, Familiares, H.I.J.O.S. y SERPAJ).

En concordancia con la trayectoria política de los directivos de las nuevas agencias gubernamentales creadas dentro del GCABA, provenientes del movimiento de DD.HH., las actividades desarrolladas por los empleados demandaron una actitud militante respecto al "trabajo por la memoria". Actitud sustentada en conceptualizaciones como la expresada por Emilio Mignone, directivo del CELS: "El mejor homenaje a las víctimas del terrorismo de Estado reside en el idealismo de los principios, la tenacidad en el esfuerzo y el realismo en la ejecución" (1991). De acuerdo a este tipo de principios, comprometerse, implica "poner el alma, el cuerpo y la mente", no sólo al servicio de las tareas confiadas sino a la "lucha de los organismos". El trabajo en la DGDH, la SSDH, y la UEPSM instruyó el compromiso con las tareas asignadas como una "forma de homenaje", promoviendo el desinterés por el sueldo recibido y la disponibilidad horaria indefinida (más allá del horario reglamentario de trabajo), así como el desarrollo de un sinnúmero de prácticas semejantes a la de los militantes políticos: pegar afiches, repartir folletos, organizar y movilizarse en marchas y actos por los DD.HH., confeccionar banderas, entre otras.

En este sentido, el compromiso operó como un componente inherente al trabajo, no detallado, que más bien que ser expresado verbalmente como un conjunto de normas éticas, fue puesto a prueba situacionalmente, apelando a ciertos valores referidos a un sistema de actitudes frente a las tareas asignadas y asumidas por los empleados. La apelación al compromiso fue movilizada en múltiples circunstancias, especialmente, cuando la dirección acordó apoyar con recursos materiales y humanos alguna propuesta de los organismos de DD.HH., y los empleados desarrollaron actividades conjuntas con militantes de DD.HH. (como la confección de una bandera con los retratos de miles de fotos de detenidosdesaparecidos, portada por los organismos de DD.HH. y sus allegados en las marchas del 24).

De modo semejante a como ha señalado Virginia Vecchioli (2009) con relación a la profesionalización de los primeros abogados de DD.HH. en Argentina, dentro del ámbito de trabajo en la CPM, la DGDH o la SSDH, el conocimiento técnico no es considerado suficiente para fundar una posición legítima como trabajador calificado en el dominio de la preservación de la memoria y la promoción de los DD.HH. Es necesario estar dotado de aquellos valores que lo equiparan a los militantes de DD.HH. La actividad profesional debe ser desinteresada, lo que implica la renuncia a la especulación salarial y/o al ascenso jerárquico. A su vez, el desinterés personal, al ser transformado en principio ético, permite poner de manifiesto las cualidades de quienes integran el plantel de trabajo, permitiendo su integración a una misma comunidad moral donde reconocerse mutuamente como "compañeros comprometidos con los DD.HH.".

Considerando las observaciones que Pitt-Rivers (1971) ha desarrollado respecto al concepto de "honor", analizamos de qué manera el compromiso con los DD.HH. ha operado en el ámbito de estas nuevas agencias gubernamentales como un "valor", al que aspirar y plausible de ser reconocido por los otros, especialmente a través de las múltiples actividades ligadas al "trabajo por la memoria". El compromiso militante con las tareas desarrolladas fue incorporado progresivamente por los trabajadores como una cualidad inherente a las actividades requeridas, un valor ambicionado y reconocible por los demás, con lo que ello conlleva de electivo y obligatorio. El compromiso con la tarea desarrollada, en este sentido, podía ser solicitado tácita o explícitamente por las autoridades, al mismo tiempo que ser reconocido por ellas y por los militantes de organismos de DD.HH. con los que periódicamente desarrollaron actividades conjuntas.

Los órganos gubernamentales (como la CPM, la DGDH, la SSDH, la UEPSM, el IEM) parecieron funcionar a modo de una escuela de formación de trabajadoresmilitantes, donde tácitamente se conjugó la noción de que "el trabajo por la memoria no es sólo un empleo". Esta conceptualización postulada por las autoridades, y promovida en la propia dinámica de trabajo junto a activistas de DD.HH., fue complementada con otra premisa, dirigida a disciplinar el trabajo de los militantes contratados como empleados del GCABA: "el trabajo por la memoria no es militancia rentada por el Estado". En otras palabras, idealmente, ser un militante no lo exime de su condición de empleado y la realización de sus actividades laborales pautadas, aunque, prácticamente, los requerimientos impuestos por su militancia en un 
organismo de DD.HH. fuesen fácilmente contemplados como "excepciones justificadas", dado el perfil de las autoridades gubernamentales provenientes del propio movimiento de DD.HH.

Estos principios complementarios (técnica y mística), muchas veces se presentaron de modo contradictorio en la práctica y generaron situaciones conflictivas al interior de los órganos gubernamentales enfocados en la "preservación y promoción de la memoria", según el componente privilegiado en determinada situación, ya sea por las autoridades y/o por el empleado. Especialmente, cuando algunos empleados expresaron su desconformidad con las condiciones de trabajo, o fueron compelidos a renunciar al empleo a partir de los cambios políticos en el Gobierno. Algunos empleados (incluso aquellos provenientes de organismos de DD.HH.) comenzaron, entonces, a manifestar otra premisa: "el trabajo por la memoria no es caridad". Por ejemplo, con motivo de la renuncia forzada de la Coordinadora de la UEPSM, los directivos propusieron a los empleados contratados durante su gestión (2000-2006) que presentaran la renuncia en bloque al GCABA, a modo de una manifestación de fuerza en apoyo político. A excepción de la Planta de Gabinete, ninguno renunció en ese momento, a pesar de que muchos lo meditaron. Como una alternativa a la renuncia, algunos empleados solicitaron la trasferencia a otra área dentro del GCABA. Pero la mayoría concibió que la propuesta era "injusta", porque a diferencia de las personas que ocupaban cargos jerárquicos, ellos no tenían "contactos políticos" que favorecieran su (re)ubicación en otras agencias estatales o no gubernamentales de DD.HH. donde el compromiso político-militante les fuera reconocido como fundamento de un trabajo asalariado, ya que esta cualidad no es suficiente para ser reclutado en otro tipo de ámbitos laborales, donde generalmente se privilegia la capacidad técnica y/o profesional de los empleados. Con base en este razonamiento, en esa ocasión, los empleados destacaron las diferencias de jerarquía interna existentes en la UEPSM y el IEM (sobre todo a nivel salarial) y demarcaron la distinción existente entre "trabajadores" vs. "funcionarios políticos". En este sentido, comenzaron a organizarse entre sí con el objetivo de garantizar sus "derechos", además de sus "obligaciones" (morales y profesionales), como empleados del GCABA y, mas específicamente, como "trabajadores del área memoria" más allá de la gestión política coyuntural. La mayoría de los empleados contratados durante la gestión de la Coordinadora de la CPM, posteriormente Directora General de DD.HH., Subsecretaria de DD.HH. y Coordinadora de la UEPSM, se afiliaron masivamente a la Asociación de Trabajadores del Estado (ATE). Quienes permanecieron como empleados de la UEPSM conformaron una comisión interna, denominada: "trabajadores de sitios de memoria". Esta iniciativa por parte de los propios empleados habilitó un ámbito dónde discutir el régimen de contratación del GCABA y las condiciones de trabajo en los distintos órganos gubernamentales orientados a preservar la memoria sobre el terrorismo de Estado y promover los DD.HH.

La creación de una comisión interna dentro de ATE y la realización de movilizaciones y paros en demanda de mejoras salariales trajeron aparejado un serio debate al interior de la CPM, la UEPSM, las respectivas CTyC y el IEM, pues los empleados señalaron que así como, en general, se les pedía "promover la memoria sobre el terrorismo de Estado y difundir los DD.HH."; en particular, se estaban desconociendo los derechos de los trabajadores en la actualidad. Los empleados del GCABA, organizados como "trabajadores de sitios de memoria" comenzaron a marcar que la noción de memoria promovida a través de los distintos proyectos en los que trabajaban cotidianamente carecía de sentido si no contemplaban la situación de los derechos en la actualidad. Mientras que para los representantes de los organismos de DD.HH. era incongruente hacer un paro en los "sitios de memoria", pues "la memoria no para". Estos conflictos expusieron que para los empleados del GCABA la "memoria" además de un compromiso militante era una fuente laboral.

Otro tema controvertido con relación al trabajo en los "proyectos de memoria" dentro del GCABA, giró en torno a los requerimientos técnicos y/o académicos solicitados a los empleados y, paradójicamente, la limitación de su rol respecto a los lineamientos de su trabajo, en tanto el objetivo de las tareas específicas respondió a las decisiones políticas generales tomadas por los representantes de la CPM o las CTyC de los sitios de memoria. Las tareas técnicas estaban contempladas en el contrato de empleo o pasantía, y su desarrollo era guiado por cada coordinador de área, el que articulaba con dichas comisiones, donde los criterios del coordinador del trabajo eran presentados, pero no necesariamente aceptados e incorporados. Esta articulación de relaciones interjerárquicas implicó muchas veces la apertura de importantes hiatos entre los resultados del trabajo técnico y las decisiones políticas arribadas por las respectivas comisiones de gestión. A modo de ejemplo, en el caso de las personas contratadas especialmente para trabajar en la confección de la nómina de desaparecidos y asesinados para el Monumento, su actividad consistió en recabar y sistematizar información proveniente de distintas fuentes sobre el destino de cada uno de ellos. Esta extensa investigación involucró el desarrollo de hipótesis de trabajo e interpretaciones generales sobre los hechos pasados que no siempre coincidieron con la posición política de los integrantes de la CPM. Este tipo de situación controversial se dio, paradigmáticamente, con relación al número de desaparecidos y asesinados en nuestro país, el cual para los técnicos no es de treinta mil, tal como reza la histórica consigna de los organismos de DD.HH.: "30.000 compañeros detenidos desaparecidos". Los encargados de la confección de la nómina sugirieron 
a los integrantes de la CPM reconsiderar la cifra, sin poner en duda la fuerza simbólica de la consiga, pero ello no fue aceptado por los representantes de los organismos de DD.HH., alegando que ella era un "hecho" y, en cuanto tal, era indiscutible. La consigna "investigar", por lo tanto, fue interpretada de diferente modo por los técnicos y la mayor parte de los representantes de los organismos de DD.HH. que integran la CPM, quienes en gran parte son los que deciden los lineamientos políticos de los proyectos de memoria. Pues, para el técnico con formación académica, investigar supone testear una hipótesis y construir conocimiento con base en ella, más bien que fundamentar una consigna política. Dentro de este marco de relaciones, la posibilidad de los empleados de nuclearse como "trabajadores de sitios de memoria", entre otras cosas, les permitió incorporarse tangencialmente en la discusión sobre la noción de "memoria" y abrir el debate sobre su participación en la toma de decisiones sobre los lineamientos de los proyectos que llevan adelante día a día.

El trabajo en el área de DD.HH. del GCABA, además de tomar como fundamento la doctrina universal de los DD.HH y situarse en las fronteras institucionales definidas por las atribuciones político-administrativas asignadas a cada área del gobierno, se caracterizó por la apelación a creencias y valores ligados a la militancia en organismos no gubernamentales de DD.HH. y el compromiso político con la "lucha por Memoria, Verdad y Justicia". El ethos de trabajo en la DGDH, la SSDH, y la UEPSM, en este sentido, fue signado por la puesta en funcionamiento de una gestión personalizada que articuló las disposiciones gubernamentales con los requerimientos de los organismos de DD.HH. En este sentido, el trabajo para realizar proyectos de memoria a través del GCABA fue vehiculizado a través de la apelación al compromiso, como valor orientador de las prácticas de los políticos y empleados involucrados en su desarrollo. Pero la apelación a este valor, no se restringió al área de DD.HH., sino que fue utilizado incluso para movilizar la propia estructura político-administrativa del gobierno. Los promotores de los proyectos de memoria realizaron un trabajo de sensibilización de los directores y trabajadores de otras áreas del GCABA (como la Secretaría de Educación, la Dirección General de Mantenimiento Edilicio, la Dirección General de Casco Histórico, entre otras) que pudieran aportar recursos humanos y materiales para su realización. A partir de visitas guiadas por los propios sobrevivientes a los lugares donde funcionaron algunos ex CCD, y reuniones conjuntas con referentes de organismos de DD.HH., los directores de las agencias gubernamentales orientadas a "preservar y promover la memoria sobre el terrorismo de Estado" procuraron involucrar personalmente a funcionarios, legisladores y empleados con el desarrollo de las obras conmemorativas (materiales e inmateriales) impulsadas por la CPM y el IEM. En otras palabras, buscaron comprometer afectivamente a todos aquellos que fueran a participar de la realización estos proyectos, más allá de la relación establecida administrativamente entre el área de DD.HH. y otras dependencias del GCABA en términos de requerimiento de su trabajo técnico. De este modo, los protagonistas del proceso de producción e implementación de las políticas públicas de memoria en la Ciudad de Buenos Aires tamizaron los requerimientos técnicos del trabajo con la lógica de la mística militante.

Buenos Aires, 30 de mayo de 2011

\section{Agradecimientos}

Este artículo se sustenta en la investigación realizada para mi tesis doctoral, titulada: "El proceso social de consagración de la memoria sobre el terrorismo de Estado como política pública estatal de derechos humanos en Argentina", Facultad de Filosofía y Letras, UBA, Argentina, pp. 365, marzo de 2011. Los datos para este trabajo fueron relevados a través de mi participación en distintas instancias de observación etnográfica, la realización de entrevistas a políticos, empleados del Gobierno de la Ciudad Autónoma de Buenos Aires, e integrantes de organismos de Derechos Humanos (DD. $\mathrm{HH}$.), y la consulta y análisis de fuentes documentales referidas al tema abordado (diarios, revistas, leyes y resoluciones gubernamentales, folletos y material de difusión de agencias gubernamentales y organismos de DD.HH.). Asimismo, dada mi experiencia pasada como empleada y gestora en el área de DD.HH del GCABA, algunos datos han sido reconstruidos y revisados a partir de la reflexión sobre mi propia trayectoria laboral.

\section{Bibliografía}

Crenzel, E. (2008) La historia política del Nunca Más. La memoria de las desapariciones en Argentina. Siglo $\mathrm{XXI}$, Buenos Aires.

Pitt-Rivers, J. (1971) The people of the Sierra. University of Chicago Press, Chicago.

Turner, V. (1980) La selva de los símbolos. Siglo XXI, México.

Vecchioli, V. (2009) Expertise jurídica y capital militante: reconversiones de recursos escolares, morales y políticos entre los abogados de derechos humanos en la Argentina. Revista Pro-Posições, v. 20, n. 2 (59), p. 41-57, maio/ago. 2009, Campinas.

Vezzetti, H. (2009) Sobre la violencia revolucionaria. Memorias y olvidos. Siglo XXI, Buenos Aires. 